\title{
Molecular genetic study of female cancers in Novosibirsk, Russia
}

\author{
Lyudmila F Gulyaeva \\ From 16th International Charles Heidelberger Symposium on Cancer Research \\ Coimbra, Portugal. 26-28 September 2010
}

Female cancers such as breast (BC), endometrial (EC) and ovarian (OC) cancers show a growing incidence rate all over the world including Russia. In Novosibirsk city the incidence of BC, EC and OC is approximately 80, 25 и 12 per 100000 in female population, respectively. In Novosibirsk population $\mathrm{EC}$ is most commonly found between the ages of 55 and 60 years, OC - between 45-60 and 55-60 years, BC - between 45-60 years. The age maximum for uterus myoma and endometrial hyperplasia was 45-50 and 40-45 years respectively. Thus, the peak incidence occurs in the post-menopausal age group for women with cancer and pre-menopausal age group for women with benign tumors. It is generally accepted that estrogens contribute greatly to the growth and development of these tumors. We estimated a frequency of allelic variants of estrogenmetabolizing enzymes CYP1A1, CYP1A2, CYP19 (aromatase) and II-phase enzyme SULT1A1 (Sulfotransferase) genes in the female Caucasian population in Novosibirsk region of Russia and their association with the elevated risk of female cancers. We have shown that for $\mathrm{BC}$ significant differences in the allele distributions for CYP1A1 M1 polymorphism between patients $(\mathrm{n}=286)$ and controls $(\mathrm{n}=$ 274) were found ( $\mathrm{OR}=2.05, \mathrm{p}=0.000004)$. There is a deficiency of a mutant allele A of CYP1A2*1F in $\mathrm{BC}$ patients $(\mathrm{OR}=0.72, \mathrm{p}=0.0023)$ as well as genotypes A/A homozygote's $(\mathrm{OR}=0.048, \mathrm{p}=0.0042)$ which exhibited a reduction of $\mathrm{BC}$ risk. Women with mutant allele $\mathrm{A}(\mathrm{OR}=2,03$, $\mathrm{p}=0.0003)$ and genotypes SULT1A1 AG heterozygote's $(\mathrm{OR}=2,22, \mathrm{p}=0.000005)$ and homozygote's $\mathrm{A} / \mathrm{A}(\mathrm{OR}=$ $4,25, \mathrm{p}=0.000004)$ of SULT1A1 gene exhibited an increase of $\mathrm{BC}$ risk. We examined how genotype was related to the risk of developing an ER-positive $\left(\mathrm{ER}^{+}\right)$and $\mathrm{PR}$-positive $\left(\mathrm{PR}^{+}\right) \mathrm{BC}$ tumor. We have shown the risk of an $\mathrm{ER}^{+}$breast

Correspondence: gulyaeva@soramn.ru Novosibirsk State University, Novosibirsk, Russia and Institute of Molecular Biology and Biophysics, Novosibirsk, Russia tumor seemed smaller for individuals with the CYP1A1, CYP19 and SULT1A1 variant allele and genotypes. The remarkable differences in the allele and genotype distributions for CYP1A2*1F polymorphism in patients with $\mathrm{OC}$ $(\mathrm{n}=125)$ were found $(\mathrm{OR}=0.26, \mathrm{p}=0.0000005)$. The frequency of a mutant CYP19 heterozygote genotype $\mathrm{C} / \mathrm{T}$ was higher in patients with $\mathrm{OC}$ and $\mathrm{EC}(\mathrm{n}=168)$ compared to healthy women $(\mathrm{OR}=3.87, \mathrm{p}=0.001$ and $\mathrm{OR}=3.73, \mathrm{p}=$ 0.0004 , respectively). The detection of estrogen-metabolizing enzymes in tumor is also important tool for the treatment and prognosis of cancer. We determined the expression of ER $\alpha, E R \beta, C Y P 19$, SULT1E1 and STS genes in studied tumors and revealed several tumor phenotypes. We have shown the $\mathrm{ER}^{+}, \mathrm{CYP} 19^{+}$phenotype in both $\mathrm{BC}$ and EC (60 and $80 \%$ cases respectively), whereas ER', CYP19- (20\% cases) phenotypes was found in BC only. We also have shown $\mathrm{ER}^{-}, \mathrm{CYP}^{+} 9^{+}$phenotype in $20 \%$ cases of $\mathrm{BC}$ and $\mathrm{EC}$ that could be important for the personalized treatment with aromatase inhibitors. The expression of STS was increased in $80 \%$ of EC tumors. Thus, studied genes could be appropriate candidates for our understanding their contribution to endocrine disorders and environmentally determined diseases susceptibility. Various patterns of $E R \alpha, \beta, C Y P 19$, STS gene expression are promising tool for the personal treatment of female cancers in additional to HER2/neu and other target genes.

\section{Acknowledgements}

This work was supported by Federal program "Research and scientificpedagogical personnel of innovation Russia in 2009-2013" code NC-543P, \# P600.

Published: 24 September 2010

\section{doi:}

Cite this article as: Gulyaeva: Molecular genetic study of female cancers in Novosibirsk, Russia. BMC Proceedings 2010 4(Suppl 2):O21. 